\title{
Heat Exposure and Physiological Changes among Cooks
}

\author{
Siti Marwanis Anua*, Mohd Nizamuddin Ismail, Mohd Amierul Aieman Mohd Nordin, Faridah Naim, Nurul \\ Ainun Hamzah, Nurul Izzah Abdul Samad
}
Environmental and Occupational Health Programme, School of Health Sciences, Health Campus, Universiti Sains Malaysia, 16150 Kubang Kerian, Kelantan, Malaysia.
*Corresponding author: smarwanis@usm.my

Article History

Received: October 28, 202 Received in revised form: December 20, 2021 Accepted: December 20, 2021 Published Online: December 25, 2021

\begin{abstract}
Cooks who are exposed to heat produced from stoves when working in the kitchen are at risk of thermal stress and heat-related illness. Physiological changes such as increased heart rate, sweat production and blood pressure may also affect them. This study aimed to determine the area heat exposure levels and physiological changes including core body temperature, blood pressure and heart rate during pre-, mid- and post-shift among cooks and its association, and to compare the mean difference of physiological changes between the shifts. This cross-sectional study utilised the purposive sampling method and recruited 30 cooks from food stalls and cafeterias in Kelantan. Area heat measurements were collected from 14 sites ( 7 inside and 7 outside the USM Health Campus). Wet-bulb Globe Temperature (WBGT) monitor was mounted on a tripod at $1.1 \mathrm{~m}$ height near the source of heat for 8 hours. The core body temperature, blood pressure, and heart rate were taken three times per day during pre, mid- and post-shift for physiological changes measurement. Respondents' personal information, health history, work description, and symptoms of heat-related illness were collected using a questionnaire. The overall WBGT area levels at each sampling site were homogeneously distributed. There was significant increase in core body temperature and heart rate from preshift to post-shift. However, there was no significant correlation $(\mathrm{p}>0.05)$ between heat exposure (WBGT index) established with the physiological changes. This may suggest that the increase in core body temperature and heart rate might be attributed to other factors and needed further investigation.
\end{abstract}

Keywords: heat exposure; physiological changes; blood pressure; core body temperature; cooks

\subsection{INTRODUCTION}

Occupational heat stress is one of the major issues in tropical countries such as Malaysia which may affect workers' health and performance. Cooks who are exposed to heat produced from stoves when working in the kitchen may be getting thermal stress and heat-related illness such as heat rash, heat cramps, heat syncope and heat stroke [1]. Other factors that may affect them are physiological changes such as increased heart rate, sweat production and blood pressure. Not only that, increase heat stress levels could lead to high workplace accidents and incidents which can be attributed to fatigue, confusion, and poor coordination due to physiological changes [2].

Occupational heat stress is may also affect the quality of life of the workforce, as well as workers' wellbeing and safety [3]. However, it is still the most neglected occupational hazard in tropical countries [4]. In addition to that, there is a lack of study in Malaysia on the heat stress in the kitchen. One of the problems faced by cooks when working in the kitchen is getting thermal stress due to heat produced from the stove. In addition to that, climate change, hot weather environments and low ambient humidity can increase the heat stress level [5]. Besides, hypo-hydration frequently occurs in occupations involved with manual tasks and particularly at workplaces with high environmental temperatures [6].

Therefore, this study will focus on heat stress levels and the physiological effects among the cooks and workers at kitchens in the area of Kubang Kerian, Kelantan. They are several stalls that only open their business during the day and also food stalls that operated only at night. Nowadays, food stalls are an important source of eateries among students and the public for their daily busy schedules and at cheap prices. On the usual occasions, students who stayed in the hostel are not allowed to 
cook their own food at the dormitory and have less time to prepare foods usually eat in restaurants or food stalls place near the university. Restaurants and food stalls that serve good food at reasonable prices may get attention from their regular customers. The increasing demand for food by the customer may increase the production of food, thus will lead to heat exposure when the cooks working in the kitchen. It is of paramount necessity to determine and compare the area heat exposure levels and physiological changes such as core body temperature, blood pressure and heart rate during pre-, mid- and post-shift among the kitchen workers.

\subsection{METHODOLOGY}

\subsection{Study design and subject recruitment}

The study design used in this research was a cross-sectional study measuring heat exposure level and the physiological changes that include core body temperature, blood pressure and heart rate among the kitchen workers. The type of sampling method utilised was purposive sampling targeting all kitchen workers who fulfilled the inclusion criteria; exposed to or working in a hot environment, aged above 17 years and worked more than six months. Selected workplaces or sampling sites were within the stall or cafeteria where the kitchen area has at least two walls surrounding the stove or place for cooking. The initial letter was given to the cooks as an initial approach for them to become respondents. A week after that, they were given a call to confirm their willingness to participate in this study. Then, an arrangement for data collection was made. The study was approved by the Human Research Ethics Committee (reference: USM/JEPeM/16110504). All study participants were provided with research information and voluntarily signed the research and publication consent forms before data collection.

\subsection{Questionnaire}

Prior to collecting the physiological data, the cooks were given an informed consent form and an interview was conducted for 10 minutes using a guided and validated questionnaire adapted from a previous study [7]. The questionnaire comprises of Section A, which is about personal information of respondent, Section B is about health history, Section C is about job details and Section D is related to the acute signs of health problems, which were completed for ten minutes.

\subsection{Workplace area heat monitoring}

A workplace walkthrough survey was conducted in identifying the source of heat and a suitable sampling site for heat exposure monitoring. For the area heat monitoring, Weight-Bulb Globe Temperature (WBGT) was placed near the source of heat at a range about $10 \mathrm{~m}$ away nearest to the kitchen. When placing the WBGT, it was ensured that there was no other things blocking the heat exposure. The WBGT was mounted on a tripod at a height of 1.1 meters ( 3.5 feet). The monitoring of heat exposure was done for 8 hours of working time in which started at 8.00 a.m. until 5.00 p.m.

\subsection{Physiological changes monitoring}

\subsubsection{Core body temperature}

Digital Ear Thermometer (Citizen CTD504, Japan) was used to measure the core body temperature of the respondents. Body temperature was recorded three times for pre-shift (8.00 a.m.), mid-shift (12.00 p.m.) and post-shift (5.00 p.m.).

\subsubsection{Blood pressure and heart rate}

A blood pressure monitor (OMRON HEM-7111, China) was used to measure the blood pressure and heart rate of the cooks. Systolic, diastolic blood pressure and heart rate were recorded three times for pre-shift (8.00 a.m.), mid-shift (12.00 p.m.) and post-shift (5.00 p.m.). Respondents were asked to have a rest for about five minutes and sit down in a quiet place, preferably at a desk or table, with arm resting on a firm surface and feet flat on the floor during taking the blood pressure and heart rate. For each time interval measurement, duplicate data was recorded.

\subsubsection{Body weight measurement}

A digital weighing scale (OMRON Karada Scan HBF-361, Japan) was used to measure the weight of respondents. This weighing scale is used to calculate the body mass index as well as to record the weight change of respondents for before works and after works (to screen for body fluid loss from body).

\subsection{Data Analysis}

There were two types of measurements variable involved in this study. There were the dependent variable and the independent variable. For the dependent variable was the heat stress level while for independent variable was core body temperature, blood 
pressure and heart rate. All data acquired from the questionnaire and measurements of the parameters were analysed using software IBM SPSS Statistics 22. Normality test by using Kolmogorov-Smirnov was used to identify the data type distributions where results showed that almost all data were normally distributed. Descriptive data analysis which is the frequency, mean, range and standard deviation of each variable of core body temperature and blood pressure were utilised. Bivariate analysis was utilised to analyse the mean difference between pre-shift, mid-shift and post-shift, ANOVA repeated measures. The statistical analysis with p-value of less than 0.05 was set as significant.

\subsection{RESULTS AND DISCUSSION}

\subsection{Sociodemographic characteristic and work description}

Table 1 shows the socio-demographic and work data of respondents. Majority of them were Malay females more than 40 years old. Ninety percent of them had secondary school education $(n=27)$ and have been working for less than 5 years at the current workplace (53\%). A number of human factors contribute to a worker's susceptibility to heat stress, such as medical conditions, increasing age, the overall level of fitness, presence of other metabolically stressful illnesses, use of medications, dehydration, alcohol intake, and individual ability to acclimatise to extreme temperature [8]. A previous study conducted among mining workers had shown that increased Body Mass Index (BMI) and depressed Volume Oxygen maximum $\left(\mathrm{VO}_{2}\right.$ max) are risk factors for heat exhaustion [9]. While the environmental factors that can contribute to heat stress are ambient temperature, low convection currents, high humidity, low evaporative loss, and high insulation levels around the body [8].

Table 1: Sociodemographic and work characteristics of the workers

\begin{tabular}{|c|c|c|c|}
\hline \multirow[t]{2}{*}{ Variables } & \multicolumn{3}{|c|}{ Frequency (\%) } \\
\hline & Café inside campus $(n=19)$ & Café outside campus $(n=11)$ & Total $(\mathrm{N}=30)$ \\
\hline \multicolumn{4}{|l|}{ Ethnicity } \\
\hline Malay & $19(100)$ & $7(63.6)$ & $26(86.7)$ \\
\hline Others & - & $4(36.4)$ & $4(13.3)$ \\
\hline \multicolumn{4}{|l|}{ Gender } \\
\hline Male & $2(10.5)$ & - & $2(6.7)$ \\
\hline Female & $17(89.5)$ & $11(100)$ & $28(93.3)$ \\
\hline \multicolumn{4}{|l|}{ Age Category (Years) } \\
\hline $18-29$ & $5(26.3)$ & $3(27.3)$ & $8(26.7)$ \\
\hline $30-39$ & $4(21.1)$ & $2(18.2)$ & $6(20.0)$ \\
\hline $40-49$ & $6(31.6)$ & $5(45.5)$ & $11(36.7)$ \\
\hline $50-59$ & $4(21.1)$ & $1(9.1)$ & $5(16.7)$ \\
\hline \multicolumn{4}{|l|}{ Education Level } \\
\hline Primary education & $2(10.5)$ & $1(9.1)$ & $3(10.0)$ \\
\hline Secondary education & $17(89.5)$ & $10(90.9)$ & $27(90.0)$ \\
\hline \multicolumn{4}{|l|}{ Years of Working Category } \\
\hline $1-5$ years & $11(57.9)$ & $10(90.9)$ & $16(53.3)$ \\
\hline $6-10$ years & $6(31.1)$ & $1(9.1)$ & $6(20.0)$ \\
\hline $11-15$ years & $1(5.3)$ & - & $1(3.3)$ \\
\hline
\end{tabular}

\subsection{Heat exposure levels}

Heat exposure monitoring was conducted at 14 different kitchens using WBGT in configuring their heat profiles. Table 2 shows the area heat index values of which had slightly exceeded the permissible threshold level $\left(28.2 \pm 0.8^{\circ} \mathrm{C}\right)$. This is according to the ACGIH threshold limit value for WBGT index of $>28.0{ }^{\circ} \mathrm{C}$ for moderate workload and when workers doing $75 \%$ work and $25 \%$ rest for each hour [10]. The mean heat exposure level of this study was much lower than the finding reported in bakeries which reached $31.6^{\circ} \mathrm{C}$ [1]. None of the individual kitchen temperatures reached the excessive heat levels. Based on the walkthrough survey, researchers further categorised the kitchens into two: cafe situated within the campus and café outside the campus. However, there was no significant difference in heat exposure between the café inside and outside campus ( $p>0.05$ ). Hence it can be summarised that all sampling sites were homogenous and had similar heat exposure. Following the walkthrough survey that has been conducted, the value of the WBGT index of more than $28^{\circ} \mathrm{C}$ might be also contributed by poor ventilation and the suction chamber (cooker hood) was not operated during the cooking process. The cooks claimed that they were not even sure whether the suction is functioning. Moreover, WBGT is relatively insensitive to the cooling effect of air movement, even against the most cost-effective intervention of increasing ventilation [11]. Unfortunately, in this study, ventilation was not measured. Radiant heat from the stove can also affect the value of WBGT. The longer the duration of using the stove, the more the amount of heat is released from the source. Direct radiant from the sunlight also may affect the WBGT value. Hence, the dry bulb thermometer must be shielded from the sun and the other radiant surfaces of the environment without restricting the airflow around the bulb [10]. 
Table 2: The heat exposure index (WBGT indoor) of the area monitored

\begin{tabular}{lcccc}
\hline \multirow{2}{*}{ Location } & $\mathbf{n}$ & \multicolumn{2}{c}{ Indoor WBGT $\left({ }^{\mathbf{0}} \mathbf{C}\right)$} & \multirow{2}{*}{$\boldsymbol{p}$-value } \\
\cline { 3 - 4 } & & Mean \pm SD & Median (IQR) & \\
\hline Café inside campus & 7 & $27.9 \pm 0.7$ & $27.8(27.4-28.8)$ & 0.786 \\
Café outside campus & 7 & $28.3 \pm 0.8$ & $28.8(27.2-28.9)$ & \\
& & & & \\
\hline All sites & 14 & $28.2 \pm 0.8$ & $28.3(27.4-28.9)$ & \\
\hline- Wet Bulb Globe Temperature, SD - Standard Deviation, IQR - Interquartile Range, Statistical Test - Independent t-test
\end{tabular}

\subsection{Reported heat related symptoms}

Table 3 provides information on the reported heat-related symptoms of the respondents. All of them reported having fatigue. More than half of them showing reported symptoms of heat exhaustion such as irregular movement, dizzy and nausea. These are also early symptoms of heat stroke. Similarly as reported by Rabiey [1], several bakery workers faced heat disorders including heat exhaustion (23 cases), heat cramps (17 cases), and heat stroke (5 cases).

Table 3: Reported heat-related symptoms

\begin{tabular}{lccc}
\hline Symptoms & n & Frequency & Percentage (\%) \\
\hline Fatigue & 30 & 30 & 100.0 \\
Irregular Movement & 30 & 25 & 83.3 \\
Dizzy & 30 & 16 & 53.3 \\
Nausea & 30 & 14 & 46.7 \\
Muscle Spasm & 24 & 2 & 8.3 \\
Fainted & 30 & 3 & 10.0 \\
\hline
\end{tabular}

\subsection{Differences in physiological changes}

Three types of physiological changes were monitored in this study: core body temperature, blood pressure and heart rate. A oneway repeated measure analysis of variance (ANOVA) was conducted to evaluate the change in physiological changes of the cooks when measured pre-, mid- and post-shift. Follow up comparisons indicated that there was a significant difference between core body temperature pre-shift $\left(36.6 \pm 0.9^{\circ} \mathrm{C}\right)$ and post-shift $\left(36.9 \pm 0.8^{\circ} \mathrm{C}\right)(\mathrm{p}=0.015)($ Table 4$)$.

Core body temperature is the best indicator to show the effect of accumulation of heat exposure [12, 13]. As body heat balance cannot be maintained in high heat stress levels, so the heat is stored in the body. Heat stored in the body will be increased when the amount of heat stress increases [14]. The mean value for core body temperature showed an increase for every time interval, however, the mean value recorded among the respondents were below $38.0^{\circ} \mathrm{C}$ in which was still within the allowable exposure range [15]. This is similar to the reported increment of core body temperature across a shift in the previous study [3]. Core body temperature will increase when in hot weather. It could also make the body difficult to function normally. This can be demanding on the body and lead to heat-related illnesses and even death.

As the majority of respondents had been working in the kitchen for one to five years (Table 1), so it can be predicted that most of the cooks had acclimatised hence can adapt to their work environment. The longer the period of employment the higher the acclimatisation to heat exposure. Full acclimatisation is achieved after seven continuous days of gradual exposure and can be up to three weeks [16]. Acclimatisation can decrease the heart rate and core body temperature reading due to the excess sweating process. Workload and environmental conditions can affect the acclimatisation process $[7,17]$.

Blood pressure is also a vital indicator for physiological changes when working in a hot environment [18], which could lead to an increase in blood pressure [19]. However, no significant differences in diastolic and systolic blood pressure across shifts were observed in this study. A significantly higher heart rate was recorded during post-shift $(85.2 \pm 8.4 \mathrm{bpm})$ compared to pre-shift $(79.0 \pm 11.9 \mathrm{bpm})(\mathrm{p}=0.003)$ among the respondents. A few studies have reported an increase in heart rate among workers who worked in the hot environments $[20,21,22]$. Heart rate is affected by ambient temperature. 
Table 4: Difference in physiological changes (pre-, mid- and post-shift)

\begin{tabular}{|c|c|c|c|c|c|}
\hline Variable & $\mathbf{n}$ & Mean \pm SD & Range & $\mathbf{F}$ & $\mathbf{p}$ \\
\hline \multicolumn{6}{|c|}{ Core Body Temperature $\left({ }^{\circ} \mathrm{C}\right)$} \\
\hline pre-shift & 30 & $36.6 \pm 0.9$ & $34.2-37.9$ & \multirow{3}{*}{4.532} & \multirow{3}{*}{$0.020^{*}$} \\
\hline mid-shift & 30 & $36.8 \pm 0.8$ & $34.2-37.9$ & & \\
\hline post-shift & 30 & $36.9 \pm 0.8$ & $35.2-37.9$ & & \\
\hline \multicolumn{6}{|c|}{ Diastolic Blood Pressure (mm Hg) } \\
\hline pre-shift & 30 & $78.2 \pm 13.8$ & $56-120$ & \multirow{3}{*}{2.333} & \multirow{3}{*}{0.116} \\
\hline mid-shift & 30 & $75.4 \pm 11.2$ & $51-100$ & & \\
\hline post-shift & 30 & $74.3 \pm 11.5$ & $51-102$ & & \\
\hline \multicolumn{6}{|c|}{ Systolic Blood Pressure (mm Hg) } \\
\hline pre-shift & 30 & $125.6 \pm 19.9$ & $99-195$ & \multirow{3}{*}{2.528} & \multirow{3}{*}{0.098} \\
\hline mid-shift & 30 & $122.4 \pm 16.7$ & $91-170$ & & \\
\hline post-shift & 30 & $121.2 \pm 17.3$ & $87-180$ & & \\
\hline \multicolumn{6}{|c|}{ Heart Rate (bpm) } \\
\hline pre-shift & 26 & $79.0 \pm 11.9$ & $58-100$ & \multirow{3}{*}{6.619} & \multirow{3}{*}{$0.005^{*}$} \\
\hline mid-shift & 26 & $82.9 \pm 7.9$ & $69-95$ & & \\
\hline post-shift & 26 & $85.2 \pm 8.4$ & $61-99$ & & \\
\hline
\end{tabular}

\subsection{Limitation of study}

There were a few limitations encountered in this study. For example non-cooperation in joining this research among the cooks approached due to busy schedule, hence the low number of participations. Generalisation on a larger scale could not be drawn thus to fix this, more respondents/sample sizes are required. Also, the measurement for the second time interval (mid-shift) varied, based on the availablility of cooks because it was conducted during their peak hour. It was hard to gather the required information at the same time due to their commitment to work. This study also focused on heat area monitoring only as there was no available equipment to measure the personal heat exposure. Hence the data analysis correlating the exposure and physiological changes/symptoms cannot be performed. Therefore, it is suggested that personal heat monitoring to be conducted among the respondents for future research work. Another parameter of measurement that should be considered to be included in future study is ventilation measurement. Hydration status of the workers such as fluid intake is also one of the important indication of heat strain as dehydration might impaired the body's thermoregulatory process and cause dangerous increases in core body temperature [23]. An attempt to collect the information on fluid intake via survey as well as determining the respondents' body weight for pre- and post-shift have been made in configuring the respondents' hydration status. However, majority of respondents did not complete the survey for the former whereas the weighing scale was not sensitive to detect the difference of the latter. It will be well worthy to have such information hence should be considered in future study.

\subsection{CONCLUSION}

In this study, it can be concluded that the overall WBGT area levels at each sampling site were homogeneously distributed. There was a significant increase in core body temperature and heart rate from pre-shift to post-shift. However, there was no significant correlation ( $\mathrm{p}>0.05$ ) between heat exposure (WBGT index) established with the physiological changes (results were not tabulated in this paper). This may suggest that the increase in core body temperature and heart rate might be attributed to other factors and needed further investigation.

This study showed only half of the area at food stalls kitchen that has high WBGT in temperature that exceeds allowed standard Threshold Limit Value recommended by ACGIH. Hence the cooks are at risk of heat stress. Serious effects from heat exposure are heat stroke and heat cramps. When a person does not get early and proper treatment, it may lead to faint and death. Thus to prevent this from occurring, the following measures can be taken into consideration:

\section{i. Engineering controls}

The first engineering control is by reducing the temperature and humidity through air cooling. Besides, provide air-conditioned rest areas for workers to decrease their core body temperature. Increase air movement (fans) if the temperature is more than 35 ${ }^{\circ} \mathrm{C}$.

\section{ii. Administrative controls}

Increase the frequency and length of rest breaks. Workers cannot be exposed to heat for too long because it may increase core body temperature. Thus, it is important to drink water without added salt, before as well as during and after work. As a starting 
point, workers should drink about two glasses ( 0.5 litres) of water before starting work in a hot environment and one glass for every 20 minutes throughout the workday. Cool drinking water should be provided near workers and to remind them to drink a cup every 20 minutes. Workers also should salt their food well, particularly while they are acclimatising to a hot job (workers will a low salt diet should discuss this with their doctor).

\section{iii. Personal protective equipment}

Light summer clothing should be worn to allow free air movement and sweat evaporation. For outside work, light-coloured clothing is recommended. Then in a high radiant heat situation, reflective clothing may help to reduce the heat trap in the cloth.

\section{Acknowledgements}

The authors would like to thank Universiti Sains Malaysia, School of Health Sciences and to all subjects who had participated in this study.

\section{References}

[1] Rabiey, R.E. 2019. Evaluation of indoor heat stress on workers of bakeries at Assiut city, Egypt. International Journal of Environmental Science and Technology, 16: 2637-2642.

[2] Hokmabadi, R., Rezaei-Hachesu, V., Kazemi, M., Fallah, H., Golbabaei, F. 2020. Occupational injuries and accidents in work environmet's heat stress exposure. Archives of Occupational Health, 4(2): 530-541.

[3] Boonruska P, Maturachon T., Kongtip P, Woskie S. 2020. Heat stress, physiological response, and heat related symptoms among Thai sugarcane workers. International Journal of Environmetal Research and Public Health, 17 (17): 6363.

[4] Nur Athirah Diyana, M. Y., Karuppiah, K, Shamsul Bahri, M.T. 2014. Heat related illness in palm oil mill workers under heat stress. Adv. Environ. Biol., $8(15): 171-176$

[5] Xiang, J., Bi, P., Pisaniello, D., Hansen, A. 2014. Health impacts of workplace heat exposure: An epidemiological review. Industrial Health, 52: 91-101

[6] Piil JF, Lundbye-Jensen J, Christiansen L, Ioannou L, Tsoutsoubi L, Dallas CN, et al. 2018. High prevalence of hypohydration in occupations with heat stress-Perspectives for performance in combined cognitive and motor tasks. PLoS ONE.13(10): e0205321. https://doi.org/10.1371/journal.pone. 0205321

[7] Nurul AH and Shamsul B. 2011. Heat stress and the relationship with physiological changes among welders in. Shah Alam, Selangor. Malaysian Journal of Public Medicine. 11(1): 47-59.

[8] Rampal L. 2000. Heat Stress in the Workplace, BUMC Proceedings. 13: 349-350.

[9] Donoghue AM, Bates GP. 2000. The risk of heat exhaustion at a deep underground metalliferous mine in relation to body-mass index and predicted VO2 max. Occupational Medicine. 50(4): 259-63.

[10] Occupational Safety and Health Administration (US). OSHA Technical Manual. $1999 . \quad$ Available from:https://www.osha.gov/dts/osta/otm/otm_iii/otm_iii_4.html\#iii:4_2 Accessed on 28th February 2016

[11] Farshad, A., Montaze,r S, Monazzam, M. R., Eyvazlou, M. Markazemi, R. 2012. Heat Stress Level among Construction Workers. Iranian Journal of Public Health. 43(4): 492-498

[12] Nag, A., Kothari, D., Desai, H. 1999. Exposure limits of women in hot environment. The Indian Journal of Medical Research. 110: 138-44.

[13] Lazaro, P., Momayez, M. 2021. Heat stress in hot undeground miners: A brief literature review. Mining, Metallurgy and Exploration, 38 : 497-508.

[14] Kenny, G. P., Yardley, J., Brown, C., Sigal, R. J. Jay, O. 2010. Heat stress in older individuals and patients with common chronic diseases. CMAJ. 182(10):1053-60.

[15] American Conference of Governmental Industrial Hygienist. 2015. Documentation of the threshold limit values for physical agents. 7th Edition. Cincinnati.

[16] WorkSafeBC. 2007. 'Preventing heat stress at work'. Workers' Compensation Board of B.C, British Columbia. Available from https://www.worksafebc.com/en/resources/health-safety/books-guides/preventing-heat-stress-at-work?lang=en

[17] Yasmeen, S., Liu, H., Wu, Y., Li, B. 2020. Physiological responses of acclimatized construction workers during different work patterns in a hot and humid subtropical area of China. Journal of Building Engineering, 30 (July 2020): 11

[18] Afriyanto, D.F. and Widajati, N. 2020. Analysis of work climate and the increase of blood pressure of construction workers in Pamekasan regency. Indian Journal of Forensic Medicine and Toxicolology, 14(3): 1076-1080.

[19] Li, L., Liu, H., Chen, L., He., J. 2019. Investigation on heat stress of construction workers in summer in Chongqing, China. E35 Web of Conference, 80(2): 6

[20] Loannou, L.G., Tsoutsoubi, L., Mantzios, K., Gkikas, G., Pii, J.F., Dinas, P.C., Notley, S.R., Kenny, G.P., Nybo, L., Flouris, A.D. 2021. The impacts of sun exposure on workers physiology and cognition: Multi-country evidence and interventions. International Journal of Environmental Research and Public Health, 18(14): 7698

[21] Zhang, S., Zhu, N., Lv, S., 2020. Human response and productivity in hot environments with directed thermal radiation. Building Environment, 187 (2021): 13

[22] Abassi, A.M., Motamedzade, M, Aliabadi, M., Golmohammadi, R., Tapak, L. 2020. The impact of indoor air temperature on the executive functions of human brain and the physiological responses of body. Health Promotion Prespectives, 9(1): 55-64.

[23] Wagoner RS, Lopez-Galvez NI, de Zapien JG, Griffin SC, Canales RA, Beamer PI. 2020. An occupational heat stress and hydration assessment of agricultural workers in North Mexico. International Journal of Environmental Research and Public Health. 12: 2102. doi:10.3390/ijerph17062102 